\title{
Applying Socio-technical Thinking in the Competitive, Agile, Lean, Data-Driven World of Knowledge Work and Smart, Service- Oriented, Customer-Centric Value Creation Ecosystems
}

\author{
Steven Alter \\ School of Management, University of San Francisco, San Francisco, 94939, USA \\ alter@usfca.edu
}

\begin{abstract}
This article responds to a need for a socio-technical systems (STS) perspective that fits in a world that has changed greatly over the decades since the socio-technical movement began. This article identifies conditions and paradoxes that limit traditional STS approaches in current business practice. A newer work system perspective (WSP) combines aspects of work system theory (WST), WST extensions, and the work system method (WSM). This WSP frames socio-technical thinking in a straightforward way that helps in describing and discussing socio-technical systems. It also provides many ideas that can help in negotiating and designing improvements. After summarizing WSP and some of its possible applications to work systems, this article uses the various topics in its title to indicate how WSP-based socio-technical thinking might be more suitable for today's world.
\end{abstract}

Keywords: Socio-technical System, Work System, Socio-technical Design, Socio-technical Thinking, Work System Theory, Work System Method.

\section{Introduction}

The home page of the website of the Fourth International Workshop on Socio-technical Perspective in IS Development (STPIS'18) said that although "the socio-technical perspective has been around for over half a century, it is often forgotten in the IS discourse today." Related views or concerns have been expressed in [1], [2], [3], [4] and elsewhere.

This article tries to embrace and build upon central STS ideas and values in a business world in which ideas in this article's overpacked title such as agile, lean, and data-driven are heard frequently, probably more frequently than sociotechnical. This article presents an approach to socio-technical thinking (STT). It uses the term STT to minimize entanglement in distinctions between different schools of STS thought (identified in [5] and elsewhere) related to "sociotechnical systems theory (STS-T), STS design (STS-D), and STS change (STS-C)" [6].

Goal and organization. The challenge at hand is to articulate an approach to socio-technical thinking that reflects the main STS values and is potentially useful for understanding, designing,

\footnotetext{
* Corresponding author

(C) 2019 Steven Alter. This is an open access article licensed under the Creative Commons Attribution License (http://creativecommons.org/licenses/by/4.0).
}

Reference: S. Alter, “Applying Socio-technical Thinking in the Competitive, Agile, Lean, Data-Driven World of Knowledge Work and Smart, Service-Oriented, Customer-Centric Value Creation Ecosystems," Complex Systems Informatics and Modeling Quarterly, CSIMQ, no. 18, pp. 1-22, 2019. Available: https://doi.org/10.7250/csimq.2019-18.01

Additional information. Author's ORCID iD: S. Alter - https://orcid.org/0000-0003-1629-638X. PII S225599221900103X. Received: 5 November 2018. Accepted: 8 February 2019. Available online: 30 April 2019. 
and improving operational systems in the current business world. The underlying assumption is that frequently repeated ideas such as the joint optimization of social and technical systems (e.g. [3, p. 321]) are not suitable in many situations, such as where it is difficult to define the social system as a system or where any semblance of a social system may be in flux, as in greenfield situations. An additional assumption is that STT needs to move beyond being an activity that is inherently limited by requiring involvement of experienced consultants or academic researchers.

This article builds on a similarly named paper [7] at STPIS'18 by explaining a form of STT that addresses the challenges in this paper's purposefully overloaded title. First it identifies conditions and paradoxes that limit STS design in some ways and diffuse its message in other ways. It summarizes a work system perspective (WSP) that combines work system theory (WST), several of the extensions of WST, and the main ideas from various versions of the work system method (WSM), a flexible systems analysis and design approach that came from the IS field and has been discussed in detail elsewhere [8], [9]. It explains how WSP supports STT and includes interests and needs of individuals and groups without forcing users and other work system participants or managers to assume the existence of separate social and technical systems. A concluding section explains how WSP-based STT addresses challenging topics related to the current business terms in the paper's title. Table 1 lists acronyms used in this article.

Table 1. Acronyms used in this article

\begin{tabular}{|c|c|c|}
\hline Acronym & Concept & Relevance \\
\hline STS & $\begin{array}{l}\text { Socio-technical } \\
\text { system }\end{array}$ & System that has human and technical components. \\
\hline STT & $\begin{array}{l}\text { Socio-technical } \\
\text { thinking }\end{array}$ & $\begin{array}{l}\text { Thinking in terms of socio-technical systems and related values without } \\
\text { necessarily conforming to ideas of a particular school of STS thought. }\end{array}$ \\
\hline WSF & $\begin{array}{l}\text { work system } \\
\text { framework }\end{array}$ & $\begin{array}{l}\text { Graphical representation of nine elements in a basic understanding of a work } \\
\text { system. }\end{array}$ \\
\hline WSLC & $\begin{array}{l}\text { work system life } \\
\text { cycle model }\end{array}$ & $\begin{array}{l}\text { Graphical representation of the iterative process by which work systems evolve } \\
\text { over time through a combination of planned change (formal projects) and } \\
\text { unplanned change via adaptations and workarounds. Those changes may include } \\
\text { changes in any element of the work system framework. }\end{array}$ \\
\hline WST & $\begin{array}{l}\text { work system } \\
\text { theory }\end{array}$ & $\begin{array}{l}\text { A three part theory for describing work systems and their evolution over time. } \\
\text { WST includes the definition of work system, the WSF, and the WSLC. }\end{array}$ \\
\hline WSM & $\begin{array}{l}\text { work system } \\
\text { method }\end{array}$ & $\begin{array}{l}\text { A flexible, semi-formal systems analysis method whose various versions apply } \\
\text { WST and WST extensions to help business professionals understand work } \\
\text { systems and participate in work system improvement projects. }\end{array}$ \\
\hline WSP & $\begin{array}{l}\text { work system } \\
\text { perspective }\end{array}$ & $\begin{array}{l}\text { A perspective for visualizing and analyzing work systems. WSP starts with } \\
\text { viewing a situation as a work system. It applies aspects of WST, WSM and } \\
\text { various WST extensions to provide a broadly applicable approach for } \\
\text { summarizing a work system and understanding it at various levels of detail. }\end{array}$ \\
\hline
\end{tabular}

\section{Conditions and Paradoxes that Limit the STS Movement}

Articles about the evolution of the STS movement and STS design reveal a variety of conditions and paradoxes that contribute to the STS movement's somewhat tenuous status today. Selected issues are presented as a series of paradoxes.

Diffusion of ideas vs. diffuseness of message. [4, p. 234] says that the underlying ideas of STS have spread to so many different domains that it has become diluted to "a banner under which many different concepts and design principles can flourish that have little relation to one another." Part of that dilution is evident from divergent concerns of different STS communities discussed in [3], [5], [10], [11]. For instance, [5] speaks explicitly about four major variants on STS theory and practice: North American STS, Australian STS, Scandinavian STS, and Dutch STS. On the other hand, the diffusion of STS ideas over many decades could be viewed as a success. For instance, [12] notes that "the work design and processes of both STS and flexible 
manufacturing have been successfully integrated into most organizations today. It is difficult to find an organization that does not encourage team work, employee participation and decision making" (p. 2) even though "STS began to disappear both academically and in practice" in the late 80 s early 90s." (p. 9).

Values vs. methods. [3] sees STS design as "more a philosophy than a methodology" (p. 317). "Throughout its history its practitioners have always tried to achieve its two most important values: the need to humanize work through the redesign of jobs and democracy at work" (p. 321). "The most important thing that socio-technical design can contribute is its value system. ... although technology and organizational structures may change, the rights and needs of the employee must be given as high a priority as those of the non-human parts of the system" (p. 338).

While emphasizing values, [3] spells out a complex method for STS design. "The objective of socio-technical design has always been "the joint optimization of the social and technical systems." .... "Relationships between the two systems, and between them and the outside environment, must also be carefully analyzed. This approach led to the development of a complex method for analyzing work systems, which went through a number of stages. Unit operations, or groups of tasks that fitted logically together into a discrete work activity, were first identified. Each of these unit operations was made the responsibility of a work group. Next, variances - problem areas where what did happen deviated from what should happen - were noted as areas for improved control by the work group." (pp. 321-322). Even though general awareness of STS values became more commonplace, the ascendancy of metaphors of agile and lean lead to questioning the suitability of such a complex STS approach.

Complexity vs. teachability and usability. This type of issue appears in many professional fields. Leading researchers in enterprise modeling (EM), an important subdiscipline of IS, co-authored a position paper called "Enterprise Modelling for the Masses - From Elitist Discipline to Common Practice" [13]. It proposed that "grassroots modelling could lead to groundbreaking innovations in EM." In the more mainstream realm of systems analysis and design, the title of [14] was "Systems analysis for everyone else: Empowering business professionals through a systems analysis method that fits their needs."

Similar issues apply to STS. It is difficult for a novice to obtain a full understanding of STS due to the simultaneous existence of different STS schools that are not reconciled conceptually. STS will continue to generate benefits for society even if it remains as semi-visible background knowledge for running organizations and as the professional domain of sophisticated consultants. Its long-term impact might be much greater if it could help more in democratizing the analysis of systems and the enactment of humanistic ideals through methods that do not require efforts of expert consultants.

Human welfare vs. managerialist focus. Almost two decades ago, [1, pp. 115-116] described the status of the STS movement as follows. "Socio-technical design is an enigma. It has offered so much and produced so little and we need to know why." ... "The socio-technical philosophy rests on two perhaps contradictory premises. The first can be called the humanistic welfare paradigm. Socio-technical methods focus on design of work systems to improve the welfare of employees." .... "The second can be called the managerial paradigm. All change (designed change) is instrumental and serves to improve the performance of the organization ... adding to shareholders values, making the business more competitive, improving the bottom line, making the organization more responsive to changing circumstances."

Traditional organizations vs. new organizational forms and practices. The STS movement's initial development occurred many decades ago, at a time when the use of computers and digital data did not come close to resembling the pervasive presence of information and communication technologies in today's business world. Most of today's businesses are much less hierarchical, much more controlled by process choices built into commercial software packages, and much more reliant on outsourced products and capabilities. 
Table 2 uses key terms packed into this article's purposefully overloaded title to highlight dissonances between today's business practices and traditional STS values and methods. Its second column summarizes areas where mainstream STS approaches may seem distant from ideas that many people in business take seriously today.

Table 2. Business topics and issues that STS should be able to address convincingly

\begin{tabular}{|c|c|}
\hline $\begin{array}{l}\text { Business } \\
\text { topic }\end{array}$ & How traditional STS may overlook or underplay the topic \\
\hline Competitive & $\begin{array}{l}\text { Traditional STS focuses more on internal issues related to work practices and less on how well } \\
\text { product/services meet or exceed customer expectations and needs. }\end{array}$ \\
\hline Agile & $\begin{array}{l}\text { With today's great push for speed, complex STS analysis seems inconsistent with strong trends } \\
\text { toward agile approaches. }\end{array}$ \\
\hline Lean & $\begin{array}{l}\text { A focus on lean may conflict with or override STS-driven attempts at joint optimization of } \\
\text { technical systems and social systems. }\end{array}$ \\
\hline Data-driven & $\begin{array}{l}\text { Data-driven organizations may place more attention on implications of data and less attention on } \\
\text { social concerns. }\end{array}$ \\
\hline $\begin{array}{l}\text { Knowledge } \\
\text { work }\end{array}$ & $\begin{array}{l}\text { The original STS research and practice focused on routine work in organizational settings. The } \\
\text { trend toward computerization of work changed the nature of both routine work and knowledge } \\
\text { work. Today, much routine work is structured through computerized systems that control major } \\
\text { aspects of work practices. Previously knowledge requirements were mostly about the content of } \\
\text { work. With computerization, knowledge requirements expanded for many forms of both routine } \\
\text { work and knowledge work because computerized tools required new types of knowledge across } \\
\text { many work domains. }\end{array}$ \\
\hline Smart & $\begin{array}{l}\text { The term smart has been attached to a wide range of objects and arrangements including smart } \\
\text { bombs, smart cards, smart houses, smart phones, and even smart cities. Smart in that sense } \\
\text { generally refers to combinations of automated information processing, self-regulation, IT-enabled } \\
\text { action in the world, and knowledge acquisition, The term smart often focuses mostly on artifact- } \\
\text { centric affordances that may direct attention away from social aspects. }\end{array}$ \\
\hline $\begin{array}{l}\text { Service- } \\
\text { oriented }\end{array}$ & $\begin{array}{l}\text { Service-orientation has many different meanings in today's business. If service is viewed as } \\
\text { performing activities for the benefit of others, then service-orientation may override internally- } \\
\text { directed social concerns. Service in a more technical sense typically seems quite distant from STS } \\
\text { values because it refers to operation or coordination through formal requests and responses. }\end{array}$ \\
\hline $\begin{array}{l}\text { Customer- } \\
\text { centric }\end{array}$ & $\begin{array}{l}\text { Customer-centricity may disrupt the traditional STS balance of the social and technical by } \\
\text { focusing more on interests of customers who may be impersonal, distant, or known only as } \\
\text { sources of demand rather than as people with human concerns. }\end{array}$ \\
\hline $\begin{array}{l}\text { Value } \\
\text { creation }\end{array}$ & $\begin{array}{l}\text { Economic activity always tries to create value. STS experts fully appreciate the importance of } \\
\text { value creation, but the idea of value creation per se may not receive a great deal of attention in } \\
\text { STS-oriented discussions that focus on joint optimization of social and technical systems. }\end{array}$ \\
\hline Ecosystem & $\begin{array}{l}\text { Traditional STS values and methods evolved in organizational settings. Business ecosystems such } \\
\text { as supply chains and value networks often operate more through impersonal transactions rather } \\
\text { than through social relations. }\end{array}$ \\
\hline
\end{tabular}

\section{Work System Perspective and Work System Method}

This article is based on a work system perspective (WSP), a set of ideas for visualizing and analyzing business situations as work systems. The core of those ideas is work system theory (WST), whose three parts are shown in Figure 1: the definition of work system, the work system framework (WSF), and the work system life cycle model (WSLC). Many related ideas have been published as a series of extensions of WST (e.g. work system axioms, work system design principles, work system design spaces, a theory of workarounds, a set of work system metamodels, and so on). Work system theory (WST) is the conceptual basis of the work system method (WSM), a semiformal systems analysis method originally designed for business professionals who want to improve the performance of IT-enabled work systems [8], [9]. Formal separation of WSM (an analysis approach) from WST (the conceptual core) and its extensions and applications organizes WSP's main ideas and separates those ideas from other ideas and 
from related approaches. It also supports further development into adjacent areas that are useful for analyzing and designing work systems. Thus, WSP as defined here refers to a perspective based on a specific set of ideas (definition of work system, WST, WSF, WSLC, WSM). In contrast, most socio-technical thinking takes a perspective that generally focuses on work systems but does not rely on those specific ideas.

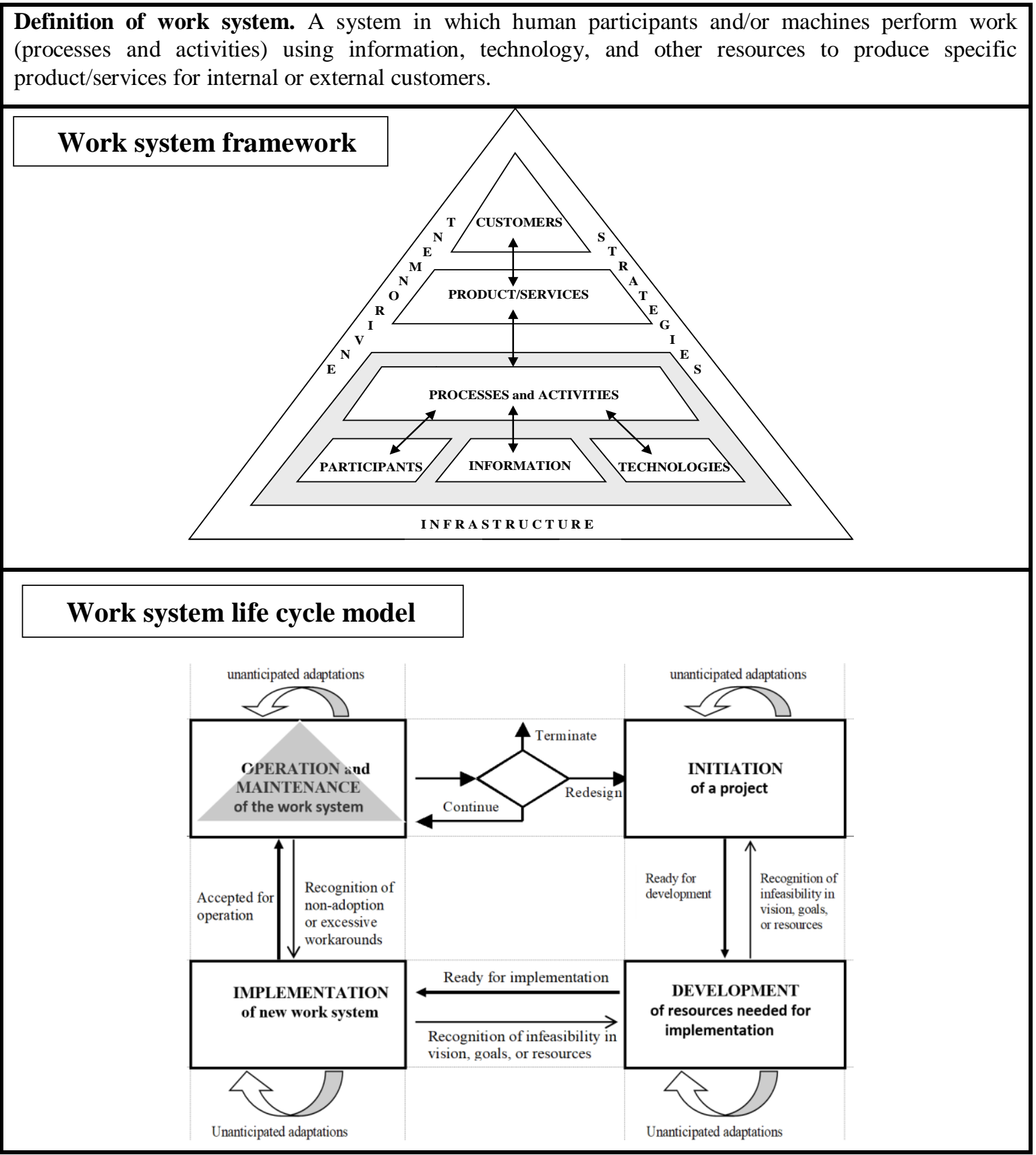

Figure 1. Three parts of work system theory: 1) the definition of work system, 2) the work system framework, 3) the work system life cycle model [9]

Definition of work system. WST defines work system in a way that allows for both sociotechnical and totally automated work systems, thereby addressing many issues related to formal modeling of systems and subsystems that could be of either type. A work system is a system in which human participants and/or machines perform processes and activities using information, technology, and other resources to produce product/services for internal and/or external customers. A work system operates within an environment that matters (e.g. national and organizational culture, policies, history, competitive situation, demographics, technological 
change, stakeholders, and so on). Work systems rely on human, informational, and technical infrastructure that is shared with other work systems. They may be governed to some extent by explicit strategies. (Note that this definition differs from definitions that treat a work system as the environment within which work is performed, e.g. descriptions of "high-performance work systems" that focus on organizational characteristics (e.g. high involvement, shared responsibility), but do not specify production processes, information, technologies or product/services).

The definition of work system implies that an information system can be viewed as a work system whose primary activities are devoted to processing information, i.e. capturing, storing, retrieving, transmitting, manipulating and/or displaying information. In organizational settings many IS exist to support other work systems. For instance, a distribution IS exists to support a work system of distributing goods. In some cases, the work systems that are supported are also information systems. For instance, an accounting information system exists to support accounting work systems whose participants include accountants. Other important special cases include supply chains, projects, and totally automated work systems. Supply chains are work systems that extend across multiple organizations to provide resources for other organizations. Projects are work systems that produce specific product/services and then go out of existence. WSP covers both socio-technical work systems that have human participants and totally automated work systems that have no human participants. It covers automated work systems because realistic analysis of many socio-technical systems may uncover partially or totally automated subsystems and may recommend that current socio-technical systems should be reconstituted in a way that isolates totally automated work systems.

An enterprise or organization can be viewed as a series of interacting work systems. That observation supports linkage between socio-technical thinking and enterprise modeling in many business situations.

Work system framework. The WSF identifies and organizes nine elements of even a rudimentary understanding a work system's form, function, and environment during a period when it is relatively stable even though incremental changes such as minor personnel substitutions or technology upgrades may occur without changing the perceived identity of the work system. Processes and activities, participants, information, and technologies are completely within the work system. Customers and product/services may be partially inside and partially outside because customers often participate in the processes and activities within work systems and because product/services take shape within work systems. Environment, infrastructure, and strategies are largely outside of the work system even though they often have direct effects within work systems and therefore are part of a basic understanding of those systems. Figure 1 places the customer on top because work systems exist for the purpose of producing product/services for customers. For socio-technical work systems this leads to trade-offs between internal management concerns about efficiency, morale, and vulnerability, versus customer concerns about the total cost to the customer, quality, and other characteristics of the product/services that they receive. Different internal vs. external trade-offs apply to totally automated systems.

Work system life cycle model. The WSLC represents the iterative process by which work systems evolve over time through a combination of planned change (formal projects) and unplanned change via adaptations and workarounds. Those changes may include changes in any element of the work system framework.

The WSLC represents planned change as projects that include initiation, development, and implementation phases. Initiation is the chartering of a project for creating or improving a work system. Development involves creation or acquisition of resources required for creation of a new work system or implementation of desired changes in an existing work system. This may include software development or acquisition, software configuration, creation or improvement of procedures, documentation, and training materials, and acquisition of other necessary resources. Implementation refers to implementation in the organization, not implementation of algorithms 
on computers. A full iteration from one operation and maintenance phase to the next phase of that type can be viewed as a transition from a version of the work system to a subsequent version.

The WSLC represents unplanned change using the inward facing arrows that represent adaptations and workarounds at each stage. The most important of those arrows is one for the operation and maintenance phase. A theory of workarounds [15] explains how work system participants identify obstacles to achieving organizational goals (and sometimes their own goals), use their knowledge to identify possible workarounds, consider the monitoring system and reward system in evaluating those possible workarounds, and then decide whether to implement a workaround. Those ideas can be restated as a rationale for compliance vs. noncompliance related to actions of work system participants. [16] explains how looking at compliance versus noncompliance sometimes reveals paradoxical situations. For instance, noncompliance may be beneficial because established practices do not cover important exceptions. Similarly, compliance may be detrimental, as when over-specified processes would force work system participants to do their work inefficiently or possibly without consideration of important internal constraints or customer needs.

Work system method. WSM, a flexible, semi-formal systems analysis approach associated with WST, was created for use by business professionals and can be used jointly by business and IT professionals in designing system improvements that may or may not involve software changes. It can be used for high-level guidance in thinking about a work system or can organize a more detailed analysis by using systems analysis templates and extensions of WST. While details have varied to suit application situations, WSM starts from the work system problems, opportunities, or issues that launched the analysis. Many hundreds of MBA and Executive MBA students in the United States, China, India, Vietnam, and possibly elsewhere have used WSM via work system analysis templates (e.g. [14]) to produce preliminary management briefings suggesting improvements in work systems in their organizations. A notable aspect of WSM is that the current and proposed systems are work systems rather than hardware/software configurations.

While details differ, every version of WSM is organized around a core: 1) identify the smallest work system that has the problem or opportunity; 2) summarize the "as-is" work system using a work system snapshot [9, p. 78], a formatted one-page summary of the work system's customers, product/services, processes and activities, participants, information, and technologies; 3) evaluate work system operation using metrics, key incidents, social relations, and other factors; 4) drill down further as necessary; 5) describe recommended changes by producing a work system snapshot of a proposed "to be" work system that will probably perform better; 6) describe likely performance improvements.

Areas of consistency between WSM and STS design approaches. The different versions of WSM share commonalities that are somewhat consistent with most STS design approaches. First, the work system's scope is a choice rather a given, typically the smallest work system that exhibits problems or opportunities that motivated the analysis. Second, the current and proposed work systems are described carefully. Third, performance gaps are identified and alleviated in relation to both internal metrics such as productivity, speed, and error rate and external metrics such as quality, cost to the customer, responsiveness, and reliability. Fourth, the analysis leads to a justified recommendation for improving the work system. Overall, WSM focuses on the structure of the work system (including processes, participants, technologies, and information) and on addressing performance gaps, key incidents, customer needs, and so on. Six Sigma techniques such as Pareto charts, fishbone diagrams, and value stream mapping are just as relevant to the analysis as IT-oriented methods. The resulting project proposal outlines activities for moving from the "as is" work system to the proposed "to be" work system. Production, improvement, or installation of software may or may not be required in order to implement the new work system. 
A single system that integrates "the social system" and "the technical system." WSP assumes that a work system should be viewed and analyzed as a system whose core includes processes and activities, participants, information, and technology. In other words, participants and technologies are viewed as part of a single system and are not typically treated separately as components of a social system and a technical system, respectively. The surrounding environment includes social topics such as organizational culture, corporate politics and policies, and demographics but is viewed as external to the work system itself.

Aside from the complexity of STS design as described earlier, a fundamental problem with the STS design approach described by [3, pp. 321-322] is that social system, technical system, work system, and joint optimization are not defined clearly. While practitioners and researchers in the socio-technical community might take these terms for granted, lack of definition for basic concepts cannot help in explaining this approach to the un-initiated, which is an essential step toward STS taking a more visible place in IS research, practice, and teaching.

A possible reason for the lack of clear definition is that the separation between the social system and technical system is largely artificial, as revealed in a figure in [17, p. 25] that separates a socio-technical work system into an abstract social system and an abstract technical system with interacting variable classes. The social subsystem includes structure and people, whereas the technical subsystem includes technology and tasks. The ideas in WST's work system framework (which places people and technologies within a single system) lead to straightforward questions about the practicality of seeing a socio-technical system as a combination of separable social and technical systems.

- Is "Structure" technical or social? Structure-in-practice (assigned to the social system by [17] is a reflection of how tasks (assigned to the technical system) are performed, not just the boxes on an organization chart. Structure in current business practice is increasingly controlled and/or constrained by the capabilities and limitations of technologies such as ERP software and networks.

- Are "Tasks" technical or social. [17] assigns tasks to the technical system even though people perform tasks that are not automated. Saying that tasks are technical makes the most sense for tasks that are highly structured, such as semiconductor manufacturing, which continues to rely on people today even though many manufacturing steps have been automated. The structuring of tasks whose sequence may be controlled by BPM or BPMlike software may seem technical even though some tasks may not be governed by business rules and may be performed in idiosyncratic ways. Less structured tasks such as medical diagnosis (which has protocols but may be performed in different sequences) and essentially creative work such as design or movie production may use a variety of tools but often seem at least as much social as technical.

- Is "Information" technical or social? The ambiguous status of information (not assigned to the social system or the technical system in [17]) contributes to the lack of clarity in the separation between the social and technical. Some information that is stored in computerized databases is easily recognized as part of a technical system, especially if the information was captured or compiled automatically. Other types of information that are essential for performing work are obviously social, such as conversations, commitments, goals, rules and regulations, institutional memory, and other types of non-computerized information.

- Is "Technology" technical or social? With the widespread use of personal computing devices and smart phones, and with the trend toward BYOD (bring your own device), social aspects of the acceptance and use of technology are increasingly important in sociotechnical systems.

Difficulty defining or separating social and technical systems makes the notion of joint optimization problematic. The concept of optimization does not fit well with organization design because the plethora of relevant factors makes it unlikely that anyone would try to find a genuinely optimal solution. (Why talk about optimization if that is an impossible dream?) A 
more appropriate term is Herbert Simon's concept of "satisficing", i.e. finding a satisfactory solution that is acceptable to most stakeholders and that allows the organization to move forward. Instead of an image of optimization, a more appropriate image is "fit" or "alignment", or in some situations, "negotiated truce." Thus, it seems misleading to view collaboration and negotiation about social impacts of processes and technologies as a form of optimization. Dutch STS researchers express this more starkly: "The isolation of social and technical system elements into separate sub-systems blocks the view of the functional relations between the two, which are at the heart of a real production system. In consequence, the concepts [of social system and technical system] destroy the very object of analysis and impede rather than foster a comprehensive understanding of organizational dynamics" [18, p. 5].

In a broader sense, maintaining the visibility of STS values and criteria does not imply the necessity or desirability of analytic distinctions between social systems and technical systems. A social system may not be amenable to "design" in the presence of rapid change, may be difficult to define meaningfully in highly transactional work systems in supply chains or ecosystems, and does not exist at all in totally automated subsystems that are increasingly common.

\section{How a Work System Perspective Based on WST and WSM Supports Socio-technical Thinking}

This section explains how specific ideas within WSP support STT (socio-technical thinking) in ways that are not evident from most versions of STS design or STS change. These ideas are stated as gerunds (e.g. treating, highlighting, supporting, etc.) to emphasize their orientation toward deliberations by people trying to understand, analyze, or design work systems. These ideas are usable by work system participants, managers, business consultants, and IT professionals (i.e. not just by STS consultants or researchers). Overall, WSP tries to retain STS values while providing a lens for visualizing, understanding, and analyzing systematic activity in teams, organizations, and even ecosystems at whatever level of detail is appropriate. Ideally, application of these ideas should support the usual expectations about STS design and STS change, such as genuine involvement (or at least representation) of everyone who should be involved in design deliberations, implementation that enables personal growth and emphasizes quality of work life, and beneficial product/services for customers.

\subsection{Treating "Work System" as the Unit of Analysis}

STS researchers and practitioners have recognized for decades that "work system" is a natural unit of analysis for thinking about systems in organizations (e.g. [3], [19]). WSP uses WST, WST extensions, and WSM to elaborate on that stance through additional concepts, models, guidelines, theories, and methods.

Using a clear definition of work system is important analytically. WST (Figure 1) defines work system in a way that is clear and reasonably easy to use, as demonstrated by its use in management briefings by many hundreds of MBA and Executive MBA students (e.g. [14]). Extensions of WST, some of which are mentioned later, provide additional ideas that are directly useful in work system visualization and analysis.

\subsection{Highlighting Human Work System Roles to Maintain Visibility of STS Values and Criteria}

The spirit of the STS movement requires attention to STS values and criteria. Including participants and customers in the work system framework leads to focusing on the human side more than typical systems analysis methods directed at producing software. The analysis of the work system should include consideration of human dignity, the quality of work life, the 
concerns of work system participants, and the human impacts of product/services that are produced. Since work systems exist to produce product/services for customers, design in the spirit of STS should consider trade-offs between internal concerns about efficiency and support of employees versus customer concerns about total cost, quality, and other product/service characteristics.

\subsection{Supporting Change Processes Through Easily Used Ideas and Methods}

STT ideas for visualizing, understanding, and analyzing systems should support different kinds of change processes and interventions that are tailored to the specifics of the situation at hand. STT should not require excessive analysis time or documentation. It should help stakeholders pursue issues at whatever level of detail is needed. The various versions of WSM all tried to do that by providing templates with easily understood questions and along with substantial freedom in deciding what order to use in answering the questions and what amount of depth to apply to specific issues.

To the extent possible, STT should aim at establishing and maintaining a mutually beneficial balance between interests and needs of work system participants, the enterprise, its customers, and of other stakeholders inside or outside of the enterprise. Even when trying to use STT fully, needs for cost control, internal efficiency, and economic viability may conflict with social interests and concerns of work system participants, customers, and other stakeholders.

WSP addresses these issues by providing an approach for understanding socio-technical systems that can be used by most business professionals, as illustrated by the use of WSM by many hundreds of MBA and Executive MBA students. WSM was designed to democratize systems analysis, thereby allowing more people to form their own views and evaluations and to be able to participate more fully in discussions about what a work system is, how well it operates, and how it should change.

\subsection{Identifying Drivers and Obstacles to Innovation and Change by Using Elements of the Work System Framework}

Every element of the work system framework (Figure 1) is part of even a rudimentary understanding of the work system's structure, operation, and environment. Furthermore, as shown in Table 3, all of those elements have direct implications related to drivers and obstacles to innovation and change related to work systems. Table 3 does not attempt to be exhaustive since many other drivers and obstacles might have been mentioned. The key point is that all nine elements of the work system framework suggest both drivers and obstacles that should be considered.

\subsection{Using the Work System Life Cycle Model to Visualize Active Involvement of Work System Participants Throughout a Work System's Evolution}

All four phases of the WSLC in Figure 1 reveal needs for involvement and highlight important topics for STT.

- Initiation phase. Basic STS values would say that people who will be affected by a significant change in the work system are stakeholders and should be involved in conversations in the initiation phase, at least through representatives who can explain their interests and concerns. Those conversations involve the impetus for the project, the identification of problems and opportunities, and the nature of project goals. WSM was originally designed to be used in this phase.

- Development phase. This phase involves the creation or acquisition of resources that are required in order to implement intended improvements in the organization. Active 
involvement of work system participants or their representatives should help in making sure that output of a development phase (new software, modification of old software, new processes, new training material) is likely to fit the situation and likely to be understood and accepted.

- Implementation phase. This phase involves implementation in the organization, including activities such as implementation planning, training, any reconfiguration that is required, and cutover to the new work system. Basic STS values say that work system participants should play a significant role in this phase. They should not feel that changes are being foisted on them without consideration of their concerns or their ability to influence the operation of the new version of the work system.

- Operation and maintenance phase. This phase is the temporary end state of adoption for a new or improved version of a work system. If it were necessary to identify a precise point of transition from a not yet adopted state to an adopted state, that point would occur at the instant when the new work system was declared fully operational. On the other hand, from the time a new work system is declared operational, it is often likely that various parts of it will change organically as the work system participants discover more effective ways to do their work and as they respond to unanticipated exceptions, contingencies, and changes in the surrounding environment. The inward facing arrow in this phase of the WSLC highlights those adaptations and workarounds. The nature and extent of adaptations and workarounds depends partly on the extent to which work system participants were involved in the other phases.

\subsection{Using Ideas Related to Adaptations, Workarounds, and Noncompliance to Visualize Implications of Minimum Critical Specification and Design Incompletion}

Cherns' socio-technical principles of minimum critical specification and design incompletion [20], [21] are especially relevant to the above comments about adaptations and workarounds. Minimum critical specification says that the design of work systems should allow work system participants to interpret their own situations and decide how to do work consistent with the requirements of whatever customers and/or other work systems are being served. Design incompletion says that design is never complete, and that the people doing the work continually adapt their practices to challenges they face.

Comments about workarounds, compliance, and noncompliance in the section on the WSLC are directly applicable here. A common reason for workarounds is that system designers did not take minimum critical specification seriously enough and over-specified the process or created user interfaces that seem exceedingly inflexible. Inadequate attention to design incompletion leads to processes and software that are presented as though etched in stone despite the high likelihood that business realities will change and that processes and software will need to change accordingly.

WSP reflects these issues in a number of ways. The WSF outlines a description of a work system as it exists during a period when its identity does not change even though minor changes may occur occasionally, such as substitutions of personnel or temporary workarounds. The inward facing arrows in the WSLC make adaptations and workarounds visible as part of the evolution of work systems. The theory of workarounds, one of the extensions of WST, provides a general explanation of how workarounds occur. Recent WSM templates call for identifying significant workarounds because they often provide evidence about desirable work system changes. 
Table 3. Drivers and obstacles to work system change organized using the work system framework

\begin{tabular}{|c|c|c|}
\hline $\begin{array}{l}\text { Element of } \\
\text { the work } \\
\text { system } \\
\text { framework }\end{array}$ & $\begin{array}{c}\text { Drivers of innovation and change in a } \\
\text { work system }\end{array}$ & $\begin{array}{c}\text { Obstacles to innovation and change in a } \\
\text { work system }\end{array}$ \\
\hline Customers & $\begin{array}{l}\text { - Unmet needs of internal or external } \\
\text { customers } \\
\text { - Customer dissatisfaction } \\
\text { - Agreement about unmet customer needs }\end{array}$ & $\begin{array}{l}\text { - Satisfied customers } \\
\text { - Customer policies or practices that conflict } \\
\text { with the change } \\
\text { - Disagreement about unmet customer needs }\end{array}$ \\
\hline $\begin{array}{l}\text { Product/ } \\
\text { services }\end{array}$ & $\begin{array}{l}\text { - Inadequate product/service performance } \\
\text { regarding cost to the customer, quality, } \\
\text { reliability, speed, customizability, } \\
\text { complexity, or other characteristics }\end{array}$ & $\begin{array}{l}\text { - Difficulty in producing fundamental } \\
\text { improvements in product/services with } \\
\text { available resources }\end{array}$ \\
\hline $\begin{array}{l}\text { Processes and } \\
\text { activities }\end{array}$ & $\begin{array}{l}\text { - Inadequate performance of processes and } \\
\text { activities regarding production cost, } \\
\text { efficiency, effectiveness, etc } \\
\text { - Inadequate structure of processes and } \\
\text { activities }\end{array}$ & $\begin{array}{l}\text { - Adequacy of the existing processes and } \\
\text { activities } \\
\text { - Lack of performance information } \\
\text { - Lack of knowledge about how to improve } \\
\text { processes and activities }\end{array}$ \\
\hline Participants & $\begin{array}{l}\text { - Knowledge and skills of participants } \\
\text { enabling new ways to do work } \\
\text { - Motivation and ambition }\end{array}$ & $\begin{array}{l}\text { - Resistance to change } \\
\text { - Lack of motivation and ambition }\end{array}$ \\
\hline Information & $\begin{array}{l}\text { - Inadequacy of existing information that is } \\
\text { used in performing processes } \\
\text { - Availability of previously unavailable } \\
\text { knowledge or information }\end{array}$ & $\begin{array}{l}\text { - Adequacy of the existing information } \\
\text { - Unavailability of knowledge and } \\
\text { information that would facilitate change }\end{array}$ \\
\hline Technologies & $\begin{array}{l}\text { - Availability of technology innovations } \\
\text { that enable improved ways of working }\end{array}$ & $\begin{array}{l}\text { - Adequacy of existing technologies in cost, } \\
\text { maintainability, and reliability } \\
\text { - Difficulty switching from current } \\
\text { technologies to new technologies }\end{array}$ \\
\hline Environment & $\begin{array}{l}\text { Conflicts involving internal politics, } \\
\text { competitive pressures, recent enterprise } \\
\text { history, demographics, technological } \\
\text { change, and so on }\end{array}$ & $\begin{array}{l}\text { - Change-resistant organizational culture } \\
\text { - External polices and regulations that } \\
\text { prevent or delay changes }\end{array}$ \\
\hline Infrastructure & $\begin{array}{l}\text { - Availability of infrastructure that } \\
\text { facilitates change }\end{array}$ & $\begin{array}{l}\text { - Infrastructure inadequacies that make } \\
\text { change more difficult }\end{array}$ \\
\hline Strategies & $\begin{array}{l}\text { - Alignment of enterprise, department, and } \\
\text { work system strategies }\end{array}$ & $\begin{array}{l}\text { - Disagreement or misalignment about } \\
\text { strategies across levels }\end{array}$ \\
\hline
\end{tabular}

\subsection{Recognizing the Importance of Technologies and Technological Change}

STT in today's business world needs to recognize the essential role of technology in almost every work system. With rapid technological changes, continued use of old technologies may not suffice in achieving business goals regardless of whether old or near obsolete technologies feel comfortable and are preferred by work system participants. Similarly, traditional, well established IT-enabled practices may not be the best practices moving forward, regardless of whether work system participants or other stakeholders like them and dislike possible changes toward different practices.

WSP probably goes further than most STS design thinking in making technologies and technological capabilities visible in the course of analysis and design. Technologies appear in the WSF and in related metamodels that provide more detailed reinterpretations the ideas in the WSF. For instance, some of the metamodels identify two guises of technologies, tools that are used by participants who perform the work and automated services that perform activities autonomously once they are launched. 


\subsection{Producing Artifacts that Support IT Work}

Almost all significant work systems operate through computerized tools and systems. STT should fit into projects that need to provide information that IT professionals can use to acquire and/or implement whatever hardware/software configurations are needed by desired work practices.

Ongoing research related to work system modeling focuses on developing flexible linkages between analysis by business professionals and modeling needs of IT professionals. The ongoing research emphasizes different purposes and degrees of specificity in work system modeling. The more informal models focus primarily on identifying the work system and its scope and providing an understandable but not necessarily detailed description of how the work system operates and how well it operates. The more formal models use modeling tools such as BPMN, ArchiMate, and entity-relationship diagrams to specify the aspects of the work system that can be specified rigorously. The linkage between the various models is a series of increasingly expressive metamodels that are all based on the central metaphor of work systems.

\subsection{Treating Value Creation as a Central STS Design Issue}

An emphasis on value creation for customers and participants is directly related to STS values even if they might seem distant at first glance. Operational work systems exist to create things of value and to facilitate value creation by internal and/or external customers (as in services). As revised in [22], the service value chain framework in Figure 2 was designed to make notions of value more explicit in WSP by providing an additional framework (beyond the work system framework in Figure 1) that adds clarifications related to responsibilities, co-production, visibility, and value capture. All of Figure 2 can be viewed and analyzed as a single work system just as different subsystems in Figure 2 (such as provider preparation or negotiation of commitments) might be analyzed as separate work systems.

The notion of value capture in Figure 2 recognizes value for both customers and providers across all of their interactions. It assumes that value for customers and providers is the sum of their value capture throughout the service value chain. Figure 2 shows how generic activities and responsibilities of providers and customers may occur before, during, and after instances of providing a product/service to a customer. The generic categories of service activities include negotiating commitments, performing set-up, handling service requests, fulfilling service requests, and performing follow-up. The framework's bilateral form assumes some degree of coproduction by providers and consumers, and therefore incorporates responsibilities of both providers and customers for internally or externally directed work systems. Attention to responsibilities is important because inadequate performance by either providers or customers undermines the best efforts of the other party, e.g. in medical care or custom software development. The vertical "lines of visibility" inside the service delivery and service consumption rectangles represent fundamental design decisions by separating things that are visible versus invisible to providers and customers. For instance, a software developer's customer might want visibility how software was tested, whereas a doctor (a provider) might want visibility of whether a patient follows medical advice. Service encounters are mutually visible, while other activities may or may not be mutually visible.

\subsection{Using Descriptive Dimensions to Characterize Possible Directions for Change}

Figure 3 outlines a design space for positioning a current or proposed work system using two continuous dimensions. The nature of the payoff goes from social to economic; operational style goes from improvisational to rule-driven (with professional knowledge work typically in the middle). Those dimensions illustrate the range of possibilities that STT should cover while maintaining visibility of STS values and criteria. In other words, analysis of a work system 
should consider the possibility that the payoff is anywhere from largely social or totally economic, especially if the work system is totally automated. Similarly, the work system may be largely improvisational, as in some kinds of creative work, or may be highly rule-driven, as in some types of manufacturing and other work requiring high reliability and repeatability.

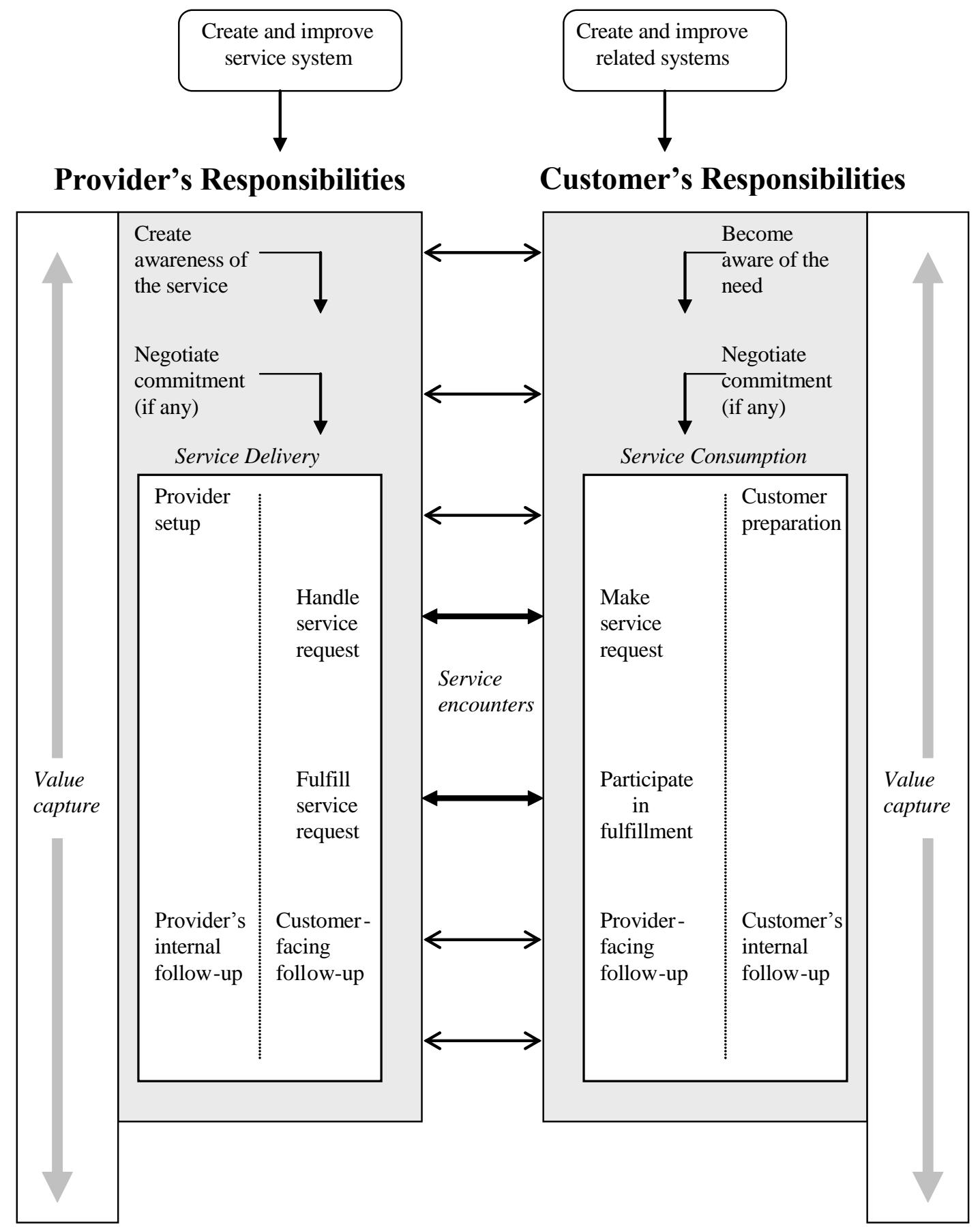

Figure 2. Service value chain framework [22] 


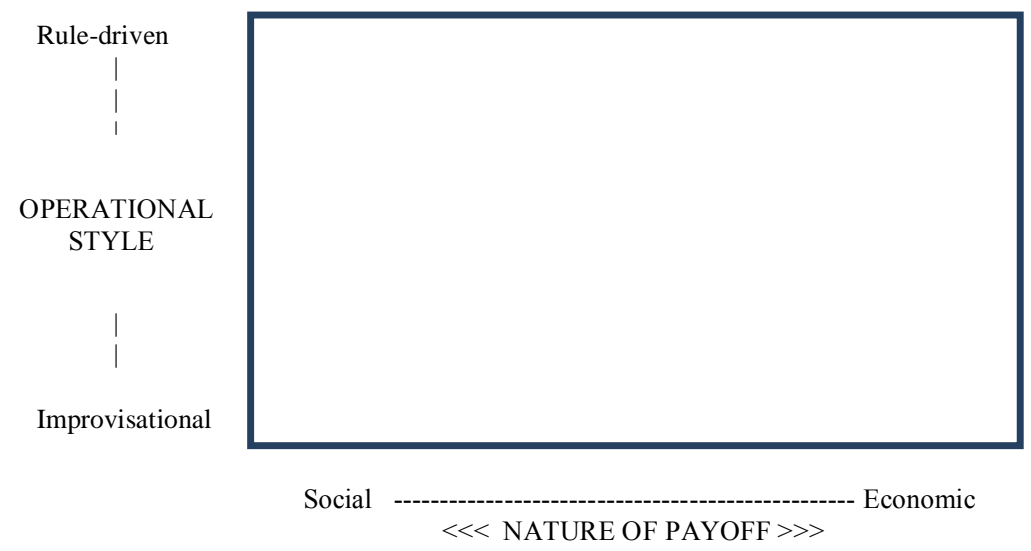

Figure 3. Positioning a work system using nature of payoff and operational style

The social to economic design dimension in Figure 3 can be expanded greatly by considering a series of design dimensions related to each of the elements of the work system framework. Table 4 lists three or more design dimensions related to each of the nine elements of the work system framework and for work system as a whole. Each of the dimensions touches on values of the STS movement and hence encourages the socio-technical thinking (STT) mentioned at the outset.

The intended use of the dimensions in Table 4 is by people deliberating about how to improve a socio-technical system that has already been identified and summarized, although individuals can use these dimensions to support their own deliberations. Collaborative use of these design dimensions could encourage work system design conversations that go beyond focusing on isolated details and isolated likes and dislikes by considering broader issues that might lead to more inclusive and innovative work system improvements.

When applied to a specific work system, each design dimension is meant to highlight STT issues and values by asking users to consider the relative presence or priority of social versus economic or technical aspects of a specific topic or issue. For instance, on a scale of 0 to 10 (from totally social to totally economic), an observer might assign a 7 to a specific work system that seems to prioritize economic issues but addresses social issues in some ways. The deliberation using that dimension would not focus on creating numerical agreement. Instead the numbers would be a starting point for thinking about tradeoffs and considering possible benefits of changing that priority by reducing it or increasing it. The value of using the dimensions comes from the deliberations they inspire, and not from the numerical assessments.

While the dimensions in Table 4 are quite numerous, students in India, Vietnam, and Germany who used a related WSM template when producing management briefings about work systems reported benefits and little difficulty in using an analogous four-page checkoff list. That list presented 113 concepts (e.g. cost to the customer, accuracy of information, uptime of technology), each of which was associated with an element of the work system framework or a work system as a whole. For each concept, the student teams were to place an X in one of 4 cells to indicate that the current work system was 1) very good in relation to the concept, 2) adequate, 3) problematic, or that the concept was not relevant. While the list of concepts seemed quite long, the teams reported having little difficulty going through the list quickly to identify issues that they might not have considered otherwise. A decade earlier, MBA and Executive MBA students reported similar reactions to similar use of a set of 24 design principles for work systems. 
Table 4. Work system design dimensions that touch on values of the STS movement

\begin{tabular}{|c|c|c|}
\hline $\begin{array}{c}\text { End point frequently associated } \\
\text { with social values }\end{array}$ & $\begin{array}{c}\text { Possible range for the } \\
\text { dimension }\end{array}$ & $\begin{array}{l}\text { End point frequently associated } \\
\text { with technical or economic values }\end{array}$ \\
\hline \multicolumn{3}{|c|}{ Work system as a whole } \\
\hline Mostly social payoff & $\langle<<0---2---4---6---8---10\rangle>$ & Mostly economic payoff \\
\hline Mostly relational & 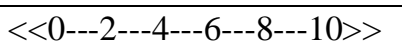 & Mostly transactional \\
\hline Mostly collaborative & $\langle<<0---2---4---6---8---10>>$ & Mostly mechanical \\
\hline \multicolumn{3}{|c|}{ Customers and Product/services } \\
\hline Providing benefits for customers & $\langle<0---2---4----6---8---10\rangle>$ & Providing products for customers \\
\hline $\begin{array}{l}\text { Product/services with no negative } \\
\text { consequences for customers, } \\
\text { ecosystem participants, or society }\end{array}$ & $\langle<<0---2---4---6---8---10>>$ & $\begin{array}{l}\text { Product/services with significant } \\
\text { negative consequences for customers, } \\
\text { ecosystem participants, or society }\end{array}$ \\
\hline $\begin{array}{l}\text { Collaborating with customers to } \\
\text { specify product/service variations that } \\
\text { meet their needs }\end{array}$ & $\langle<0---2---4---6---8---10>>$ & $\begin{array}{l}\text { Producing and selling commodity } \\
\text { product/services }\end{array}$ \\
\hline $\begin{array}{l}\text { Customizing semi-standard products } \\
\text { to suit customer needs }\end{array}$ & $\langle<<0---2---4---6---8---10>>$ & $\begin{array}{l}\text { Producing and selling commodity } \\
\text { product/services }\end{array}$ \\
\hline \multicolumn{3}{|c|}{ Processes and activities } \\
\hline Improvisational & $\langle<0---2---4---6----8---10>>$ & Rule-driven \\
\hline Low level of automation & $\langle<<0---2---4----6---8---10\rangle>$ & Highly automated \\
\hline Co-production and value co-creation & $\langle<<0---2---4---6---8---10>>$ & Production and delivery \\
\hline High reliance on social relations & $\langle<<0---2---4----6---8---10>>$ & Low reliance on social relations \\
\hline Production planned participatively & 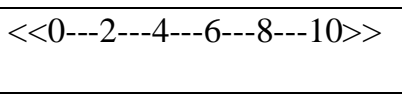 & $\begin{array}{l}\text { Production plans driven by outside } \\
\text { requirements }\end{array}$ \\
\hline $\begin{array}{l}\text { Processes governed by norms and } \\
\text { collaboration }\end{array}$ & $\langle<<0---2---4---6---8---10>>$ & $\begin{array}{l}\text { Processes governed by externally } \\
\text { imposed standards }\end{array}$ \\
\hline \multicolumn{3}{|c|}{ Participants } \\
\hline Participants treated as social groups & $\langle<<0---2---4---6---8---10>>$ & $\begin{array}{l}\text { Participants treated as mechanical } \\
\text { components }\end{array}$ \\
\hline $\begin{array}{l}\text { Concern for personal welfare of } \\
\text { participants }\end{array}$ & $\langle<<0---2---4---66---8---10>>$ & $\begin{array}{l}\text { Little concern for personal welfare of } \\
\text { participants (e.g. sweatshops, child } \\
\text { labor) }\end{array}$ \\
\hline $\begin{array}{l}\text { Reliance on personal knowledge, } \\
\text { skill, and ambition }\end{array}$ & $\langle<00---2---4---6---8---10>>$ & Reliance on computerized algorithms \\
\hline $\begin{array}{l}\text { Personal identity of participants } \\
\text { matters in the ecosystem }\end{array}$ & $\langle<<0---2---4---6---8---10>>$ & $\begin{array}{l}\text { Personal identity of participants is } \\
\text { unimportant in the ecosystem }\end{array}$ \\
\hline \multicolumn{3}{|c|}{ Information } \\
\hline $\begin{array}{l}\text { Conversations, social commitments, } \\
\text { and other social information are } \\
\text { important }\end{array}$ & $\langle<<0---2---4---6---8---10>>$ & $\begin{array}{l}\text { Conversations, social commitments, } \\
\text { and other social information are } \\
\text { unimportant }\end{array}$ \\
\hline $\begin{array}{l}\text { Use of computerized databases } \\
\text { balanced with use of } \\
\text { noncomputerized information }\end{array}$ & 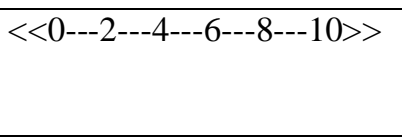 & $\begin{array}{l}\text { Computerized databases viewed as a } \\
\text { single, consistent source of truth }\end{array}$ \\
\hline $\begin{array}{l}\text { Schedules and commitments are } \\
\text { linked to specific groups or } \\
\text { individuals }\end{array}$ & $\langle<0---2---4---6---8---10>>$ & $\begin{array}{l}\text { Schedules and commitments are } \\
\text { impersonal }\end{array}$ \\
\hline \multicolumn{3}{|c|}{ Technologies } \\
\hline $\begin{array}{l}\text { Viewing work as human activity and } \\
\text { viewing technology as an enabler }\end{array}$ & $\langle<<0---2---4---6---8---10>>$ & $\begin{array}{l}\text { Viewing work as activity performed } \\
\text { by computers and other devices }\end{array}$ \\
\hline $\begin{array}{l}\text { Emphasizing interactions between } \\
\text { people }\end{array}$ & $\langle<<0---2---4---6---8---10>>$ & $\begin{array}{l}\text { Emphasizing interactions between } \\
\text { people and computerized devices or } \\
\text { just between computerized devices }\end{array}$ \\
\hline $\begin{array}{l}\text { Seeing value as a product of human } \\
\text { work }\end{array}$ & $\langle<<0---2---4----6---8---10>>$ & $\begin{array}{l}\text { Seeing value was a product of } \\
\text { technology applications }\end{array}$ \\
\hline
\end{tabular}




\begin{tabular}{|c|c|c|}
\hline $\begin{array}{c}\text { End point frequently associated } \\
\text { with social values }\end{array}$ & $\begin{array}{c}\text { Possible range for the } \\
\text { dimension }\end{array}$ & $\begin{array}{l}\text { End point frequently associated } \\
\text { with technical or economic values }\end{array}$ \\
\hline \multicolumn{3}{|c|}{ Environment } \\
\hline $\begin{array}{l}\text { Not governed by external laws, } \\
\text { regulations, standards }\end{array}$ & $<<0---2---4---6---8---10>>$ & $\begin{array}{l}\text { Governed primarily by external laws, } \\
\text { regulations, standards }\end{array}$ \\
\hline Governed by social norms & $\langle<0$---2----4---6---8----10>> & Not governed by social norms \\
\hline $\begin{array}{l}\text { Not constrained by economic } \\
\text { competition }\end{array}$ & $\langle<<0---2---4---6---8---10>>$ & $\begin{array}{l}\text { Severely constrained by economic } \\
\text { competition }\end{array}$ \\
\hline $\begin{array}{l}\text { Not touched significantly by } \\
\text { technological trends }\end{array}$ & $\langle<<0---2---4---6---8---10\rangle>$ & $\begin{array}{l}\text { Affected significantly by } \\
\text { technological trends }\end{array}$ \\
\hline \multicolumn{3}{|c|}{ Infrastructure } \\
\hline $\begin{array}{l}\text { Supported by shared human } \\
\text { infrastructure }\end{array}$ & $\langle<<0---2---4---6---8---10>>$ & $\begin{array}{l}\text { Not supported by shared human } \\
\text { infrastructure }\end{array}$ \\
\hline $\begin{array}{l}\text { Not dependent on shared } \\
\text { informational infrastructure }\end{array}$ & $\langle<<0---2---4---6---8---10>>$ & $\begin{array}{l}\text { Dependent on shared informational } \\
\text { infrastructure }\end{array}$ \\
\hline $\begin{array}{l}\text { Not dependent on shared technical } \\
\text { infrastructure }\end{array}$ & $\langle<0---2---4---6---8---10>>$ & $\begin{array}{l}\text { Dependent on shared technical } \\
\text { infrastructure }\end{array}$ \\
\hline \multicolumn{3}{|c|}{ Strategies } \\
\hline $\begin{array}{l}\text { Guided by work system strategies } \\
\text { primarily related to social issues }\end{array}$ & $\langle<<0---2---4---6---8---10>>$ & $\begin{array}{l}\text { Guided by work system strategies } \\
\text { primarily related to economic or } \\
\text { technical issues }\end{array}$ \\
\hline $\begin{array}{l}\text { Work system strategies determined } \\
\text { by largely social processes involving } \\
\text { work system participants }\end{array}$ & $<<0---2---4---6---8---10>>$ & $\begin{array}{l}\text { Work system strategies imposed } \\
\text { downward by higher level } \\
\text { management. }\end{array}$ \\
\hline
\end{tabular}

\section{Fit of WSP-Based Thinking with Today's Business World}

This article's title combined a selection of system-related terms that are probably used more frequently in today's business world than socio-technical system. The previous sections presented ideas that could foster socio-technical thinking (STT) in today's business world. This section looks at terms in the title (competitive, agile, lean, data-driven, and so on) and summarizes how the work system perspective expressed by WST and WSM fits with those terms. In the following, a term in parentheses after each topic from the title identifies a part of WST or WSM that applies most directly when thinking about that topic

Competitive. (WSF - environment) WSM is designed for use in situations where opportunities or problems call for describing, analyzing and improving work systems. The first issue is to identify the work system that has the problems and opportunities that launched the analysis. Other initial questions involve identifying both internal and metrics related to key areas of performance for the work system and describing the gap between the current and desired performance levels. The internal metrics involve efficiency, speed, and consistency issues such as production costs, resource utilization, cycle time, error rate and rework rate. External metrics related to customer perceptions of the product/services produced touch on issues such as cost to the customer, quality perceived by the customer, reliability, fit with customer requirements, and quality of the customer experience. Most of those topics have direct or indirect implications related to competitive challenges from the environment.

Agile. (WSLC - initiation, development, implementation) WSM can be viewed as an agile approach because it always keeps customers in mind (through locating the customer at the top of the work system framework) and because it can be used in varying degrees of depth and with varying amounts of documentation depending on user and stakeholder needs.

[23] reports on an experiment to determine whether producing a work system snapshot (a onepage work system description used in WSM) would help undergraduate students learn the SCRUM method for agile software development. A carefully controlled pedagogical experiment involving 160 undergraduate students found that students who produced a work system snapshot 
at the beginning of their analysis produced fewer erroneous "user stories." Some form of replication with IS professionals obviously is needed, but the experiment seems to be a step forward in research related to improving the efficiency and effectiveness of agile development. In addition, application of WSM may help in making a work system more agile if the problem is defined as a lack of flexibility, adaptability, or customer focus.

Lean. (WSF - processes and activities; WSLC - initiation, development, implementation) The idea of lean can be used in WSM as part of its analysis of processes and activities. The relevant line of questions involves the extent to which work system participants, managers, and other stakeholders believe that the work system conforms with or diverges from goals or expectations related to lean operation of the work system.

The idea of lean is also relevant to WSM itself because it can be used by individuals or teams at different levels of depth without requiring extensive resources. WSM can be used even when STS experts or consultants are not available, although the analysis results would likely be better if STS experts were available.

Data-driven. (WSF - information) All work systems use or create informational entities that are captured, transmitted, stored, retrieved, manipulated, updated, displayed, and/or deleted by processes and activities. While traditional STS analysis certainly used data to analyze "variances," being data-driven in an operational sense entails sustained focus on collecting information and using it for operational decisions and management control. WSM assumes that data is initially defined in a somewhat informal way, such as saying that the relevant data consists of orders, invoices, warranties, schedules, income statements, reservations, and so on. Detailed analysis of the data requires careful attention to data definitions and coding of data. That often goes beyond the typical notions of socio-technical analysis, especially if the data needs to be consistent with data definitions and data coding in related work systems elsewhere in the organization, regardless of what might be preferred within the local situation.

Knowledge work. (WSF - processes and activities) STS researchers sometimes characterize differences between routine work, hybrid work such as projects, and nonroutine work. (e.g. [24], [25]). WSM does not attempt to categorize work as routine work versus knowledge work. The work within a work system is described using the term processes and activities because that work may or may not involve clearly specified steps whose beginning, sequential flow, and end are defined well enough to call it a business process. Cherns' principle of minimum critical specification [20], [21] presents a challenge in analyzing or designing a work system because of the temptation to build too much control into software. Different types of processes and activities involve different degrees of structure. The range of possibilities starts with largely unstructured creative processes (such as many design and management processes) and includes semi-structured knowledge processes (such as medical diagnosis or legal analysis), workflow processes (such as invoice verification or reimbursement), and highly structured processes (such as pharmaceutical and semiconductor manufacturing). Those types of processes differ in the extent to which the sequence of activities, adherence to specified business rules, and reliance on knowledge and discretion are viewed as essential [26].

Smart. (WSF - technologies) The vastly overused term "smart" has been applied to different things in different ways. For instance, smart has been applied to objects such as smart cards, smart phones, smart watches, and smart toothbrushes; it has been applied to systems such as sensor-based data collection systems or manufacturing systems; and it has been applied to aggregations of systems such as a farms, companies, and cities. In general, an entity might be described as smart (often more in an advertising or promotional sense than in a scientific sense) if it contains at least some capabilities for some combination of information processing, selfregulation, action in the world, and/or knowledge acquisition. [27] uses those four categories to organize 23 design dimensions related to different degrees of smartness (e.g. one dimension under information processing is the degree of smartness in capturing data; another is the degree of smartness in displaying data). 
WSM treats technologies in two ways, as is expressed in various versions of work system metamodels that reinterpret the work system framework to support more detailed analysis. First, technologies can be seen as tools that are used by work system participants. Alternatively, they can be seen as automated services, i.e. totally automated work systems that perform work autonomously and return results, more or less analogous to outsourcing. In application areas where the technology seems to display a non-trivial degree of smartness, a challenge when using WSM is to deal insightfully with partial or total automation of work currently done by people, especially if they may not be able or willing to imagine automation of important aspects of their work.

Service-oriented. (WSF - product/services, customers) Inclusion of customers and product/services in the work system framework encourages focus on how a work system's customers attain value from whatever is produced and discourages excessive inward focus on how work is done in local settings. Inclusion of those terms is a reminder that work systems produce product/ services such as information, physical things, and/or actions for the benefit and use of their customers. Ignoring what a work system produces is tantamount to ignoring its effectiveness. The term "product/services" bypasses controversial marketing and service science distinctions between products and services that are not important for understanding operational work systems. Note, however, that product-like vs. service-like can be used as the basis of a series of valuable design dimensions for characterizing and designing whatever a work system produces (e.g. tangible vs. intangible, transactional vs. relational, commodity-like vs. customized, produced vs. co-produced, and so on). Those design dimensions are analogous to the design dimensions in Table 3 except that the extreme points are product-like vs. service-like instead of social vs. economic or technical.

Customer-centric. (WSF - customers) Customers are recipients of a work system's product/services for purposes other than performing work activities within the work system. WSM is designed to consider both internal and external customers, what they want, and how they use whatever the work system produces. A first challenge for WSM is to follow STS principles in a genuine way and to try to assure that customers receive product/services that provide genuine benefit. Another challenge is that a work system's customers sometimes serve as work system participants. Participation by customers is especially common in service-oriented systems whose activities are coproduced (e.g. patients in a medical exam, students in an educational setting, and clients in a consulting engagement). In such instances, many customers, and possibly significant subgroups of customers with divergent concerns, may not be able to participate in design-related discussions.

Value creation. (WSF - processes and activities, product/services, customers) The term value has many different meanings ranging from value added (i.e. the value of resources consumed) through exchange value (such as price) and value-in-use (the fact that different people may value the same object quite differently based on their use of it, independent of price).

A WSM analysis often tries to reduce the resources used or increase the exchange value of whatever is produced. Understanding value-in-use is a more difficult problem because usage of product/services by customers may not be visible and may vary greatly between customers or groups of customers.

An aspect of value creation called value co-creation has received increasing emphasis in the last decade, especially due to the development of successive refinements of service-dominant logic (S-D logic) [28], [29], [30]. The WSP view of co-production by providers and customers and of value co-creation is expressed by several metamodels that treat those concepts as follows:

- Co-production occurs when actor roles in one or more activities in a provider's work system are performed by both noncustomer participants (e.g. a doctor or a teacher) and customer participants (e.g. a patient or a student).

- Value co-creation occurs wherever one or more of the customer work system's valuecreating activities (e.g. trying to recover from an accident or trying to learn a skill) coincide 
with activities in a provider's work system (e.g. providing physical therapy or providing an educational experience).

- Co-production may occur without value co-creation if a co-production activity occurs outside of the customer work system, e.g. negotiation by customer and provider representatives about scheduling meetings related to producing custom software for a customer work system.

That approach to value co-creation reflects the view in [31] that customers create value for themselves and that providers may seize the opportunity to facilitate that value creation. That view contradicts Vargo and Lusch's (2016) S-D logic view that "cocreation of value, unlike coproduction, is not optional."

Ecosystem. (WSF - environment) The theme of ecosystems has seen increasing prominence in recent papers and discussions related to information systems. [32] notes that "the STS approach encapsulates work and the infrastructure used to do it within organizations (either explicitly or implicitly) — often leading to a "container" view of organizations as the context of work." [32] suggests updating the conceptualization of socio-technical systems "to reflect the role of information infrastructures as an enabler of trans-organizational work arrangements." Two recent articles based on research at MIT CISR (Center for Information System Research) speak of thriving or surviving in digital ecosystems [33], [34]. [35] explores differences between biological and organizational ecosystems. A third version of service-dominant logic from marketing scholars [30] emphasizes the increasing importance of understanding value cocreation in the context of business ecosystems.

WSP sees a business ecosystem as a set of interacting work systems owned by different individuals or enterprises. Most of the ideas in WSP apply equally to work systems within a firm and to work systems that cross organizational boundaries, including supply chains. A WSPbased analysis would identify the processes and activities that are co-located and the other processes and activities that require coordination across distances. Even superficial analysis would likely identify issues related to social and geographical distance that might be difficult for traditional STS approaches. A work system analysis would be able to deal with business ecosystems that are largely transactional and operate with little or no social interaction or mutual attention to humanistic values. It could also deal with collaborative ecosystems that bring analytical challenges including how to define the relevant work systems, how to obtain accurate information from independent actors with divergent incentives, and how to treat competition within the ecosystem.

\section{Conclusion}

This article showed how socio-technical thinking based on the WSP single-system view (based on WST and WSM) addresses aspects of a fast-moving business world that the original STS design efforts typically did not encounter. This article focused on a way to look at work systems themselves rather than on ideas about STS design or change processes, both of which are covered well by existing knowledge and practice. The work system perspective described here (including WST, WSM and related extensions) outlines an approach to work systems within and across organizations that may be useful to the STS community. That single-system approach (seeing an integrated work system, not separate social and technical systems) maintains awareness of interests of human participants, work system customers, and STS values even as digitization and automation expand to new applications that would have been difficult for most STS pioneers to imagine. 


\section{References}

[1] F. Land, "Evaluation in a Socio-Technical Context," Proceedings of the IFIP TC9 WG9, Organizational and Social Perspectives on Information Technology, vol. 3, 115-125. 2000. Available: https://doi.org/10.1007/978-0-387-35505-4_8

[2] E. Mumford, "Socio-technical design: An unfulfilled promise or a future opportunity?" Proceedings of the IFIP TC9 WG9, Organizational and Social Perspectives on Information Technology, vol. 3, pp. 33-46, 2000. Available: https://doi.org/10.1007/978-0-387-35505-4_3

[3] E. Mumford, "The story of socio-technical design: Reflections on its successes, failures and potential," Inf. Syst. J., vol. 16, no. 4, pp. 317-342, 2006. Available: https://doi.org/10.1111/j.1365-2575.2006.00221.x

[4] K. Eason, "Afterword: The past, present and future of sociotechnical systems theory," Appl. Ergon., vol. 45, no. 2, pp. 213-220, 2014. Available: https://doi.org/10.1016/j.apergo.2013.09.017

[5] F. M. van Eijnatten, A. B. Shani, and M. M. Leary, "Sociotechnical Systems: Designing and Managing Sustainable Organizations," Handbook of organization development, T.G. Cummings, (Ed.) Sage; 2008.

[6] D. Austrom and C. Ordowich, "North American Design of Nonroutine Work Systems (1980s-1990s)," Cocreating humane and innovative organizations: Evolutions in the practice of socio-technical system design, B. J. Mohr, B. J., and P. Van Amelsvoort, (Eds.), Global STS-D Network Press, pp 37-51, 2016

[7] S. L. Alter, "Applying Sociotechnical Thinking in the Competitive, Agile, Lean, Data-Driven World of Routine Work, Knowledge Work, and Smart, Service-Oriented, Customer-Centric Value Creation Ecosystems", Fourth International Workshop on Sociotechnical Perspective in IS Development (STPIS'18), Talinn, Estonia 2018, CEUR Workshop Proceedings 2107, vol.2107, pp.56-70, 2008.

[8] S. Alter, The Work System Method: Connecting People, Processes, and IT for Business Results. Larkspur, CA: Work System Press, 2006.

[9] S. Alter, "Work System Theory: Overview of Core Concepts, Extensions, and Challenges for the Future," J. Assoc. Inf. Syst., vol. 14, no. 2 February, pp. 72-121, 2013. Available: https://doi.org/10.17705/1jais.00323

[10] G. Baxter and I. Sommerville, "Socio-technical systems: From design methods to systems engineering," Interacting with Computers, vol. 23, no. 1. November, pp. 4-17, 2011. Available: https://doi.org/10.1016/j.intcom.2010.07.003

[11] B. J. Mohr and P. van Amelsvoort, Cocreating Humane and Innovative Organizations: Evolutions in the Practice of Sociotechnical System Design, Global STSD Network Press. 2016.

[12] S. Winby, S. "The adaptive work system: a perspective on the evolution of socio-technical systems," SocioTechnical Roundtable annual conference. New Orleans, LA, 2011.

[13] K. Sandkuhl, H. G. Fill, S. Hoppenbrouwers, J. Krogstie, F. Matthes, A. Opdahl, G. Schwabe, Ö. Uludag, and R. Winter, "From Expert Discipline to Common Practice: A Vision and Research Agenda for Extending the Reach of Enterprise Modeling," Bus. Inf. Syst. Eng., vol. 60, no. 1, pp. 69-80, 2018. Available: https://doi.org/10.1007/s12599-017-0516-y

[14] D. Truex, S. Alter, and C. Long, "Systems analysis for everyone else: Empowering business professionals through a systems analysis method that fits their needs," Eur. Conf. Inf. Syst., 2010.

[15] S. Alter, "Theory of Workarounds," Comm. Assoc. Inf. Syst., vol. 34, no. 55, March, pp. 1041-1066, 2014. Available: https://doi.org/10.17705/1CAIS.03455

[16] S. Alter, "Beneficial Noncompliance and Detrimental Compliance: Expected Paths to Unintended Consequences," Amer. Conf. Inf. Syst., 2015.

[17] R.P. Bostrom and J. S. Heinen, "MIS problems and failures: a socio-technical perspective, part II: the application of socio-technical theory," MIS Q., vol. 1, no. 1, pp.11-28, 1977. Available: https://doi.org/10.2307/249019

[18] L. Ulbo de Sitter, J. Friso den Hertog, B. Dankbaarl, "From complex organizations with simple jobs to simple organizations with complex jobs," Hum. Rel., vol. 50, no. 5, pp. 497-534, 1997. Available: https://doi.org/10.1177/001872679705000503

[19] E. L. Trist, "The Evolution of Socio-Technical Systems: A Conceptual Framework and Action Research Program” Occasional Paper No. 2. Ontario, Canada: Ontario Quality of Working Life Centre, 1981.

[20] A. Cherns, "Principles of Sociotechnical Design", Hum. Rel., vol. 29, no. 8, pp. 783-792, 1976. Available: https://doi.org/10.1177/001872677602900806 
[21] A. Cherns, "Principles of Sociotechnical Design Revisted," Hum. Rel., vol. 40, no. 3, pp. 153-161, 1987. Available: https://doi.org/10.1177/001872678704000303

[22] S. Alter, "Viewing Systems as Services: A Fresh Approach in the IS Field," Comm. Assoc. Inf. Syst., vol. 26, no. 11, pp. 195-224, 2010. Available: https://doi.org/10.17705/1CAIS.02611

[23] N. Bolloju, S. Alter, A. Gupta, S. Gupta, and S. Jain, "Improving Scrum User Stories and Product Backlog Using Work System Snapshots,” Amer. Conf. Inf. Syst., 2017 Proc., pp. 1-10, 2017.

[24] C. H. Pava, Managing new office technology: An organizational strategy. Simon and Schuster, 1983.

[25] D. Austrom and C. Ordowich, “Calvin Pava’s Legacy: Sociotechnical Systems Design for the Digital Coal Mines”. Working paper, Indiana Univ., 2018.

[26] S. Alter and J. Recker, "Using a work system perspective to expand BPM research use cases," J Info. Tech. And Tech. Appl., vol. 18, no. 1, pp. 47-71, 2017.

[27] S. Alter, "Making Sense of Smart Living, Working, and Organizing Enhanced by Supposedly Smart Objects," IFIP w. g. 8. 6 workshop, pp. 1-14, 2018.

[28] S. L. Vargo and R. F. Lusch, "Evolving to a New Dominant Logic for Marketing," J. Mark., vol. 68, no. 1, pp. 1-17, 2004. Available: https://doi.org/10.1509/jmkg.68.1.1.24036

[29] S. L. Vargo and R. F. Lusch, "Service-dominant logic: Continuing the evolution," J. Acad. Mark. Sci., vol. 36, no. 1, pp. 1-10, 2008. Available: https://doi.org/10.1007/s11747-007-0069-6

[30] S. L. Vargo and R. F. Lusch, "Institutions and axioms: an extension and update of service-dominant logic," J. Acad. Mark. Sci., vol. 44, no. 1, pp. 5-23, 2016. Available: https://doi.org/10.1007/s11747-015-0456-3

[31] C. Grönroos, "Value co-creation in service logic: A critical analysis," Mark. Th., vol. 11, no. 3, pp. 279-301, 2011. Available: https://doi.org/10.1177/1470593111408177

[32] S. Winter, N. Berente, J. Howison, and B. Butler, "Beyond the organizational 'container': Conceptualizing 21st century sociotechnical work," Inf. and Org., vol. 24, no. 4, pp. 250-269, 2014. Available: https://doi.org/10.1016/j.infoandorg.2014.10.003

[33] P. Weill and S. L. Woerner, "Thriving in an Increasingly Digital Ecosystem," MIT Sloan Manag. Rev., vol. 56, no. 4, pp. 27-34, 2015.

[34] P. Weill and S. L. Woerner, "Surviving in an Increasingly Digital Ecosystem," MIT Sloan Manag. Rev., vol. 59m, no. 2, pp.26-28A, 2018.

[35] M. Mars, J. Bronstein, and R. Lusch, "The value of a metaphor: Organizations and ecosystems," Org. Dyn., vol. 41, no. 4, pp. 1-31., 2012 Available: https://doi.org/10.1016/j.orgdyn.2012.08.002 